\title{
ISB News January 2010
}

\author{
(C) ISB 2009
}

\section{From the Chair of the Student and New Professionals Interest Group}

It is with great pleasure that I have taken over the role of leading the Student and New Professionals Interest Group (SNP) of the ISB from Dr. Kate Bassil. Firstly, I would like to thank Kate for her hard work during the early stages of setting-up the SNP. We are a new and evolving section of the ISB made up of students and new professionals, with the aim of establishing a network of colleagues at the early stage of their research and/or academic careers. We first met together at the $18^{\text {th }}$ International Congress of Biometeorology in Tokyo, September 2008. Since then, we have embarked upon our first project, which we hope to complete at the end of this year. Other future projects of the SNP may include collaborative grants, jointpublications and educational activities. We are also making plans for a Special Issue of International Journal of Biometeorology, which SNP members will be invited to submit articles to for consideration for publication.

The SNP represents a vibrant and developing section of the ISB which already includes numerous members from internationally different institutions and diverse areas within the field of Biometeorology. In many ways, we represent the future of the ISB and I believe that increasing this diversity will strengthen our network and increase the opportunities for collaborative research within the group. As such, we would like to extend a warm and open invitation to all interested student and new professionals with an interest in Biometeorology to join the SNP. Furthermore, there is still the opportunity for new members to become involved with our current project. To join the SNP, you must first be a member of the ISB, which is now free for students (with no IJB subscription). You can join the ISB at www.biometeorology.org/members/. For more information on the SNP or to join us, please feel free to contact me.

Finally, let me take this opportunity to wish you all a Happy New Year and to pass on my best wishes for the year ahead.

Simon N. Gosling Chair of the ISB SNP

s.n.gosling@reading.ac.uk 